\title{
Incidence of Ventricular Arrhythmias in Association with Left Ventricular Dyssynchrony in Chronic Ischemic Patients
}

\author{
AHMED GAMAL, M.Sc.*; AHMED DAWOOD, M.D.*; AHMED AL-HABAA, M.D.**; \\ TAREK BASSIONY, M.D.**; MOHAMED ABD EL-HADY, M.D.* and YOUSSEF NOSIR, M.D.** \\ The Departments of Cardiology, National Heart Institute* and Faculty of Medicine, Al-Azhar University**, Cairo, Egypt
}

\begin{abstract}
Background: Intra ventricular mechanical dyssynchrony may play an important role in ventricular arrhythmogenesis in chronic ischemic patients.

Aim of the Study: To detect the prevalence of ventricular arrhythmia in chronic ischemic patients in association with left ventricular dyssynchrony assessed by left ventricular longitudinal strain.

Methods: The study included 50 patients with ischemic heart disease confirmed by coronary angiography. Speckle tracking echocardiography was performed. Patients were divided into 2 groups according to presence or absence of left ventricular mechanical dyssynchrony, considering difference in time to peak $\geq 130 \mathrm{~ms}$ by longitudinal strain between any two opposing segment at basal and mid level in LV 12 segments positive for mechanical dyssynchrony. Every patient in both groups underwent 24 hours holter monitoring for detection of ventricular arrhythmia.

Results: The study results showed that there were 45 males and 5 females. Mean age \pm SD was $51.00 \pm 7.06$ years. Mean heart rate was $76.92 \pm 13.29$ beat/minute. Patients were divided into 2 groups. Group I included 40 patients with left ventricular dyssynchrony and mean time to peak SD was $102.5 \pm 34.16 \mathrm{~m} \mathrm{sec}$ and Group II included 10 patients without left ventricular dyssynchrony and mean time to peak SD was $82.3 \pm 45.1 \mathrm{msec}$. 24 hours ECG Holter monitoring data showed that there was higher incidence of ventricular runs in Group I with positive dyssynchrony patients $(47.5 \%)$ than those in Group II with negative dyssynchrony patients (20\%).
\end{abstract}

Conclusion: Left ventricular dyssynchrony assessed by left ventricular longitudinal strain could be a predictor for increased risk of ventricular arrhythmia.

Key Words: Ventricular arrhythmia - Left ventricular dyssynchrony - Longitudinal strain - Speckle tracking echocardiography.

\section{Introduction}

CORONARY Artery Disease (CAD) is a leading cause of death worldwide. Most of patients die

Correspondence to: Dr. Ahmed Gamal, The Department Cardiology, National Heart Institute, Cairo, Egypt due to Congestive Heart Failure (CHF) or Sudden Cardiac Death (SCD) which occurs due to ventricular arrhythmia [1]. Left Ventricular Ejection Fraction (LVEF) was considered an important factor for risk stratification of SCD [2,3], but it is discovered that it is not sensitive enough as studies shown that most of patients with SCD had preserved EF and not identified for ICD implantation $[4,5]$.

Cardiac dyssynchrony means disturbance of ordered sequence of cardiac contraction and relaxation leading to mechanical and electrical heterogeneity which may lead to development of ventricular arrhythmia and SCD [6-9]. Speckle tracking echocardiography is relatively a new technique for assessment of left ventricular strain and left ventricular dyssynchrony. Therefore, the aim of our study was to detect the incidence of ventricular arrhythmia in chronic ischemic patients in association with left ventricular dyssynchrony assessed by left ventricular longitudinal strain.

\section{Patients and Methods}

The study was conducted at the Cardiology Department, Al-Azhar University Hospitals, and National Heart Institute during the period between February 2016 and February 2017. The study included 50 patients with stable ischemic heart disease and sinus rhythm. Informed consent was given by all patients for participation in the study. Exclusion criteria from the study included patients with Acute Coronary Syndrome (ACS), acute heart failure, significant valvular lesion, Chronic $\mathrm{Ob}$ structive Pulmonary Disease (COPD) and significant arrhythmia that may interfere with study analysis (e.g: AF). Patient with abnormal kidney function and patients with poor echo window were also excluded from the study. 


\section{Coronary angiography:}

Every patient had coronary angiography to confirm presence of ischemic heart disease. CAD was considered significant if $\geq 70 \%$ stenosis.

\section{Echocardiography and 2 dimensional (2-D)} speckle tracking study:

All patients were examined in left lateral position using machine (XMATRIX iE 33 Philips) and trasnsducer (Probe 5-1) Standard two dimensional and Doppler echocardiography were performed, apical four, three and two chamber views were obtained by both grey scale and 2D speckle tracking technique and digitalized for offline analysis. Visual assessment of the regional LV systolic function

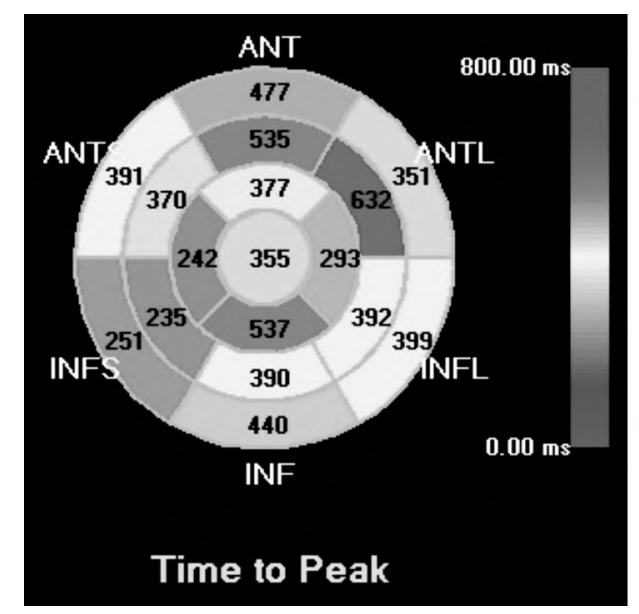

Fig. (1): Patient with LV dyssynchrony by left ventricle longitudinal strain. Difference in time to peak betw een 2 opposing segments $\geq 130 \mathrm{~ms}$.

\section{Holter monitoring:}

24 hour of Holter monitoring was performed for every patients within 1 to 3 days from echocardiography provided that patient clinical condition and medications remained unchanged, looking for ventricular arrhythmia.

\section{Statistical analysis:}

Data were collected, coded and entered to the Statistical Package for Social Science (IBM SPSS) Version 20. Qualitative data were presented as number and percentages while quantitative data were presented as mean, Standard Deviations ( $\pm \mathrm{SD}$ ) and ranges when parametric and median with interquartile range with non parametric data. The comparison between the two groups with qualitative data were done by using Chi-square test and/or Fisher exact test was used instead of Chi-square test when the expected count in any cell was found less than 5 . was performed using the 12 segment model and 5 score index at time of examination. Calculation of Ejection Fraction (EF) was performed by 2-D modified Simpson method. Calculation of global longitudinal strain from apical four, three and two chambers STE views. Each wall was divided into 3 segments: Apical, mid and basal. Longitudinal dyssynchrony was defined as maximum opposing wall delay in time to peak strain among the three apical views from basal and mid-level using cut off $\geq 130 \mathrm{~ms}$ and is considered as significant dyssynchrony [10] . Patients were divided into two groups according to presence or absence of LV dyssynchrony. Group I included 40 patients with dyssynchrony, and Group II included 10 patients without dyssynchrony Figs. $(1,2)$.

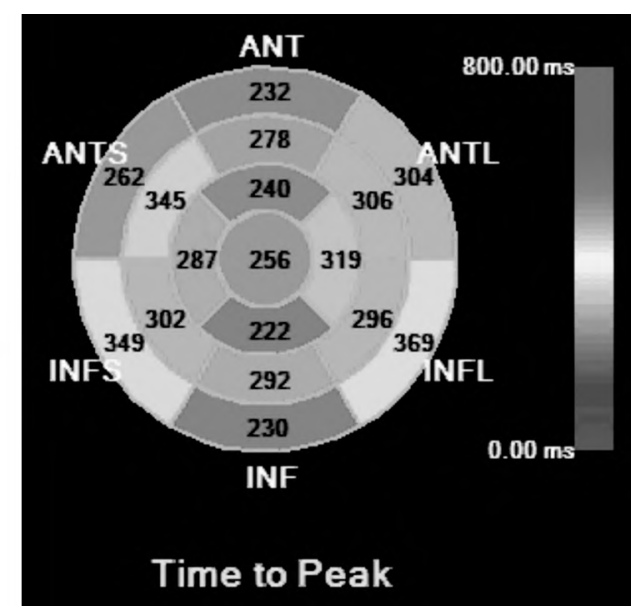

Fig. (2): A patient without LV dyssynchrony by left ventricle longitudinal strain.

The comparison between the two groups regarding quantitative data with parametric distribution was done by using Independent $t$-test and also data with non parametric distribution was done by using Mann-Whitney test.

The confidence interval was set to $95 \%$ and the margin of error accepted was set to 5\%. So, the pvalue was considered significant as that $p<0.05$; and $p<0.01$ : Highly significant.

\section{Results}

Study included 50 patients with chronic ischemic heart disease. Patients were divided into two groups, Group I with left ventricular dyssynchrony and Group II without dyssynchrony assessed by left ventricle longitudinal strain.

\section{Demographic data:}

Group I included 40 patients, 36 males (90\%) 4 females $(10 \%)$. The mean of age \pm SD was 
$51.65 \pm 7.6$ years. Group II included 10 patients, 9 males $(90 \%) 1$ female $(10 \%)$. The mean of age \pm SD was $48.40 \pm 3.27$ years (Table 1 ).

Table (1): Demographic characteristics of patients in both groups.

\begin{tabular}{lllll}
\hline & Group I & Group II & \multicolumn{2}{c}{ Chi-square test } \\
\cline { 4 - 5 } & $\mathrm{N}=40$ & $\mathrm{~N}=10$ & $\chi^{2} / t^{*}$ & $p$-value \\
\hline Age $(y r s):$ & & & & \\
$\quad$ Mean \pm SD & $51.65 \pm 7.61$ & $48.40 \pm 3.27$ & $-1.312^{*}$ & 0.196 \\
Range & $33-65$ & $43-51$ & & \\
Sex: & & & & \\
Females & $4(10.0 \%)$ & $1(10.0 \%)$ & 0.000 & 1.000 \\
Males & $36(90.0 \%)$ & $9(90.0) \%$ & & \\
\hline
\end{tabular}

\pm SD: Standard Deviation.

Group I included 24 hypertensive patients (60\%), 20 diabetics (50\%) and 17 dyslipidemic (42.5\%). Group II included 3 hypertensive patients $(30 \%)$. 4 diabetics (40\%) and 6 dyslipidemic $(60 \%)$ (Table 2).

Table (2): Risk factors of both groups of patients.

\begin{tabular}{lllll}
\hline & \multirow{2}{*}{$\begin{array}{c}\text { Group I } \\
\mathrm{N}=40\end{array}$} & $\begin{array}{c}\text { Group II } \\
\mathrm{N}=10\end{array}$ & \multicolumn{2}{c}{ Chi-square test } \\
\cline { 5 - 5 } & & & $\chi^{2} / t^{*}$ & $p$-value \\
\hline HTN: & & & & \\
$\quad$ No & $16(40.0 \%)$ & $7(70.0 \%)$ & 2.899 & 0.089 \\
Yes & $24(60.0 \%)$ & $3(30.0 \%)$ & & \\
Dyslipidemia: & & & & \\
No & $23(57.5 \%)$ & $4(40 \%)$ & 0.986 & 0.321 \\
Yes & $17(42.5 \%)$ & $6(60 \%)$ & & \\
Smoking: & & & & \\
No & $19(47.5 \%)$ & $6(60 \%)$ & 0.500 & 0.480 \\
Yes & $21(52.5 \%)$ & $4(40 \%)$ & & \\
DM: & & & & \\
No & $20(50.0 \%)$ & $6(60 \%)$ & 0.321 & 0.571 \\
Yes & $20(50.0 \%)$ & $4(40 \%)$ & & \\
FH: & & & & \\
No & $18(45.0 \%)$ & $5(50 \%)$ & 0.081 & 0.777 \\
Yes & $22(55.0 \%)$ & $5(50 \%)$ & & \\
\hline
\end{tabular}

HTN : Hypertension.

DM : Diabetes Mellitus.

FH : Family History.

\section{Coronary angiography data:}

Group I included 33 patients (82.5\%) with LAD lesion, 20 patients (50\%) with LCX lesion and 22 patients $(55 \%)$ with RCA lesion. There was more prevalent LAD lesion and the presence of LV dyssynchrony, while in Group II there was 4 patients $(40 \%)$ with LAD lesion, 6 patients $(60 \%)$ with LCX lesion and 5 patients $(50 \%)$ with RCA lesion, (Table 3).
Table (3): Distribution of CAD in both groups.

\begin{tabular}{lcccc}
\hline \multirow{2}{*}{$\begin{array}{l}\text { Coronary } \\
\text { artery affected }\end{array}$} & \multirow{2}{*}{$\begin{array}{c}\text { Group I } \\
\mathrm{N}=40\end{array}$} & $\begin{array}{c}\text { Group II } \\
\mathrm{N}=10\end{array}$ & \multicolumn{2}{c}{ Chi-square test } \\
\cline { 4 - 5 } & & & $\chi^{2} / t^{*}$ & $p$-value \\
\hline $\begin{array}{l}\text { - Left anterior } \\
\text { descending }\end{array}$ & $33(82.5 \%)$ & $4(40 \%)$ & 7.510 & 0.006 \\
$\begin{array}{l}\text { - Left circumflex } \\
\text { artery }\end{array}$ & $20(50.0 \%)$ & $6(60.0 \%)$ & 0.321 & 0.571 \\
$\begin{array}{l}\text { - Right coronary } \\
\text { artery }\end{array}$ & $22(55.0 \%)$ & $5(50.0 \%)$ & 0.081 & 0.777 \\
\hline
\end{tabular}

Relation between number of CAD lesions and prevalence of ventricular arrhythmia in both groups:

In Group I patients with LV dyssynchrony, the prevalence of ventricular arrhythmia was progressively related to the number of CAD. In patients with 3 vessels disease significant ventricular arrhythmia was found in 9 patients out of 14 patients $(64 \%)$, and that is much higher than that patients with 2 vessels disease 3 out of $6(50 \%)$ higher than that patients with single vessel disease 7 out of 20 $(35 \%)$ (Table 4).

Table (4): Relation between number of CAD lesions and prevalence of ventricular arrhythmia in both groups.

\begin{tabular}{cccc}
\hline & $\begin{array}{c}\text { 1 vessel } \\
\text { disease }\end{array}$ & $\begin{array}{c}2 \text { vessels } \\
\text { disease }\end{array}$ & $\begin{array}{c}3 \text { vessels } \\
\text { disease }\end{array}$ \\
\hline $\begin{array}{c}\text { Group I } N=40: \\
\text { Positive VT runs }\end{array}$ & 7 & 3 & 9 \\
$\begin{array}{c}\text { Group II } N=10: \\
\text { Positive VT runs }\end{array}$ & 1 & 0 & 1 \\
\hline
\end{tabular}

Conventional echocardiography and speckle tracking data:

In Group I the mean Ejection Fraction (EF) was $49.65 \pm 9.55 \%$. Resting Wall Motion Abnormality (RWMA) was detected in 30 patients $(75 \%)$. The mean \pm SD of GLS was -17 . The mean of Time to peak SD was $102.5 \pm 34.16 \mathrm{~ms}$ (Table 5).

Group II showed that EF was mean was $49.90 \pm$ $11.22 \%$. RWMA detected in 6 patients (60\%). The GLS median was 17.5. The time to peak SD mean was $82.3 \pm 45.1 \mathrm{~ms}$ (Table 5).

There was no statistical significant difference between both groups as regards echocardiographic and speckle tracking data (Table 5).

\section{Twenty-four Holter ECG data:}

Group I showed that mean QTc according to Bazett"s formula was $439.7 \pm 39.25 \mathrm{~ms}$. Ventricular runs were detected in 19 patients $(47.5 \%)$. Ventricular bigeminy was detected in 6 patients $(15 \%)$. 
Ventricular trigiminy was detected in 4 patients $(10 \%)$. $\mathrm{R}$ on $\mathrm{T}$ ectopics were detected in 2 patients $(5 \%)$.

Table (5): Difference between both groups as regarding echocardiographic parameters.

\begin{tabular}{|c|c|c|c|c|}
\hline & \multirow{2}{*}{$\begin{array}{l}\text { Group I } \\
\mathrm{N}=40\end{array}$} & \multirow{2}{*}{$\begin{array}{c}\text { Group II } \\
\mathrm{N}=10\end{array}$} & \multicolumn{2}{|c|}{ Chi-square test } \\
\hline & & & $\chi^{2} / t^{*}$ & $p$-value \\
\hline $\begin{array}{l}E F: \\
\quad \text { Mean } \pm \text { SD } \\
\quad \text { Range }\end{array}$ & $\begin{array}{l}49.65 \pm 9.55 \\
30-65\end{array}$ & $\begin{array}{l}49.90 \pm 11.22 \\
30-60\end{array}$ & $0.072 *$ & 0.943 \\
\hline $\begin{array}{c}R W M A: \\
\text { No } \\
\text { Yes }\end{array}$ & $\begin{array}{l}10(25.0 \%) \\
30(75.0 \%)\end{array}$ & $\begin{array}{l}4(40 \%) \\
6(60 \%)\end{array}$ & 0.893 & 0.345 \\
\hline $\begin{array}{l}G L S: \\
\text { Median (IQR) } \\
\text { Range }\end{array}$ & $\begin{array}{l}-17(-19--15) \\
-27--3\end{array}$ & $\begin{array}{l}-17.5(-18--14) \\
-20--5\end{array}$ & $0.714 *$ & 0.729 \\
\hline $\begin{array}{l}\text { Time to peak } \\
S D(m s): \\
\text { Mean } \pm \mathrm{SD} \\
\text { Range }\end{array}$ & $\begin{array}{l}102.5 \pm 34.16 \\
44-170\end{array}$ & $\begin{array}{l}82.3 \pm 45.1 \\
42-162\end{array}$ & $0.063 *$ & 0.063 \\
\hline $\begin{array}{ll}\text { EF } & \text { : Ejectior } \\
\text { RWMA : Resting } \\
\text { GLS } & \text { : Global } \\
\pm \text { SD } & : \text { Standar }\end{array}$ & $\begin{array}{l}\text { n Fraction. } \\
\text { Wall Motion Ab } \\
\text { Longitudinal Str } \\
\text { d Deviation. }\end{array}$ & $\begin{array}{l}\text { normality. } \\
\text { ain. }\end{array}$ & & \\
\hline
\end{tabular}

Group II showed that mean QTc interval was $426.93 \pm 19.72 \mathrm{~ms}$. Ventricular runs were detected in 2 patients $(20 \%)$. Ventricular bigiminy was dete-

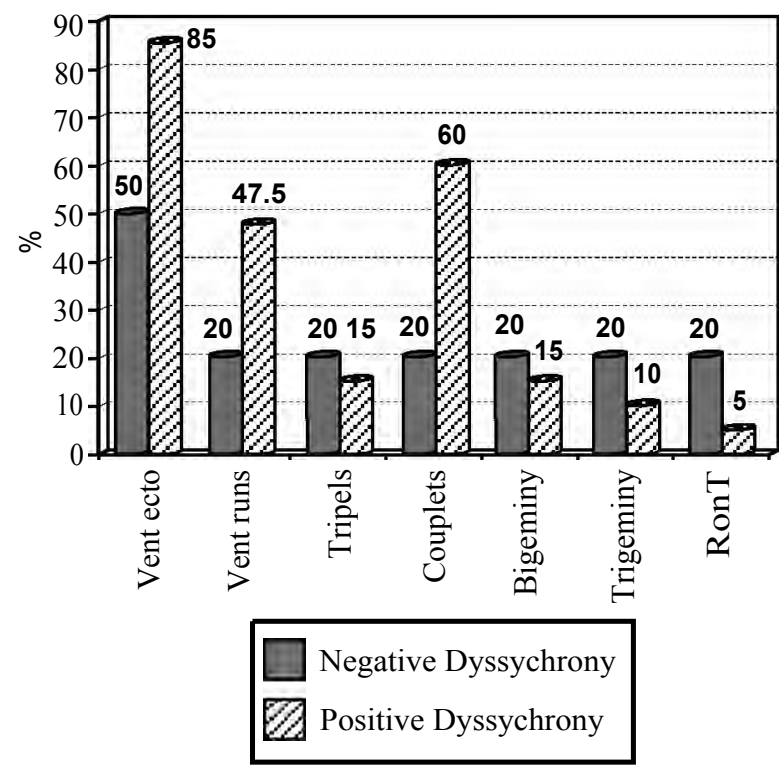

Fig. (3): Incidence of different types of ventricular arrhythmia in both groups.

Vent. ecto.: Ventricular ectopics. vent. runs: Ventricular runs.

cted in 2 patients $(20 \%)$ ventricular trigiminy was detected in 2 patients $(20 \%)$. $\mathrm{R}$ on $\mathrm{T}$ ectopics were detected in 2 patients (20\%) Graph (1) (Table 6).

Table (6): Twenty four hour Holter ECG obtained data in both groups.

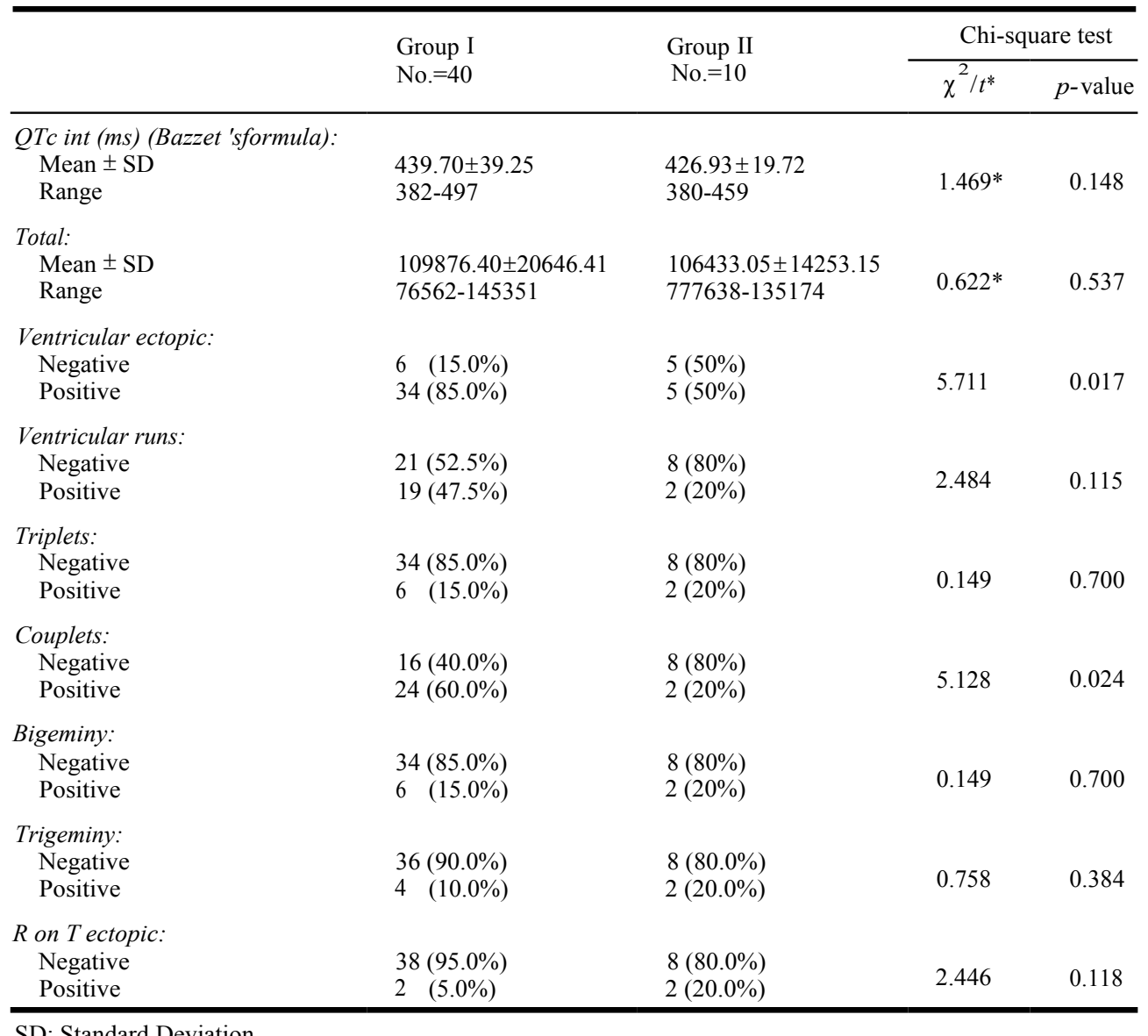

SD: Standard Deviation. 
Our data shows that there was significant statistical difference between both groups as regards to frequency of both premature ventricular contractions and ventricular couplets (Table 6).

Our data shows that there was a trend for higher prevalence of ventricular runs in Group I than Group II, (47.5\%) versus (20\%) respectively (Table 6).

\section{Discussion}

This study evaluated the prevalence of ventricular arrhythmias in patients with chronic ischemic heart disease, and showed increased risk of ventricular arrhythmia in association with LV dyssynchrony.

The study showed that the presence of significant lesion in left anterior descending artery was associated with increased incidence of left ventricular dyssynchrony.

We found that there was statistically significant difference between both groups as regards to the frequency of both ventricular ectopics and ventricular couplets.

The study demonstrated that there was a trend for higher incidence of ventricular runs in Group I with left ventricular dyssynchrony (19 patients $47.5 \%$ ) than Group II with negative dyssynchrony (2 patients 20\%).

There was no statistical significant difference in both groups regarding ejection fraction. This result agreed with the study conducted by Haugaa et al., [11] on 85 post myocardial infarction patients. They found that EF did not differ between patients with and without ventricular arrhythmias occurring during follow-up.

Our results agreed with the study conducted by Leong et al., [12]. On the relationship between left ventricular dyssynchrony and the risk of ventricular arrhythmia post MI. Their study included a total of 206 patients with prior MI. Speckletracking echocardiography for assessment of dyssynchrony by global longitudinal strain and Implantable Cardioverter Defibrillator (ICD) implantation which was retrospectively evaluated. Patients were followed-up for the occurrence of Ventricular Tachycardia (VT) for about 24 months. In total, $75(36.5 \%)$ individuals experienced runs of VT They concluded that LV dyssynchrony is a good factor for prediction of occurrence of VT after MI.
Haugaa et al., [11] conducted a study which included 85 post myocardial infarction patients, 44 meeting primary and 41 meeting secondary ICD prevention criteria. After about 2 years of followup, 47 patients had no ventricular arrhythmia and $38(44.7 \%)$ patients had recorded arrhythmias requiring appropriate ICD therapy. Longitudinal strain was measured by speckle tracking echocardiography. They found that mechanical dyssynchrony was greater in ICD patients with recorded ventricular arrhythmias compared with those patients without ventricular arrhythmia.

Bader et al., [13] had a study on heart failure patients and reported that left ventricular dyssynchrony was a prognostic marker of ventricular arrhythmia by tissue Doppler technique.

Tayal et al., [14] had a study on mechanical dyssynchrony by tissue Doppler and whether left ventricular dyssynchrony was associated with higher risk of ventricular arrhythmias after Cardiac Resynchronization Therapy (CRT) or not. Their study included 151 CRT-D patients that were prospectively included. They demonstrated that persistent and new mechanical dyssynchrony after CRT-D was associated with subsequent ventricular arrhythmia. In another study conducted by Cho et al., [15], they demonstrated that mechanical dyssynchrony was a powerful predictor of mortality or cardiac events in heart failure patients with normal and wide QRS complex.

Relation between left ventricular dyssynchrony and ventricular arrhythmia in non ischemic dilated cardiomyopathy was studied by Haugaa et al., [16]. 94 patients with non ischemic dilated cardiomyopathy were prospectively included. By speckletracking strain echocardiography, mechanical dyssynchrony was assessed by global longitudinal strain. After a median of 22 months of follow-up, patients with arrhythmic events had increased mechanical dyssynchrony. They concluded that mechanical dyssynchrony is a promising marker for prediction arrhythmic events in patients with dilated cardiomyopathy independently of LVEF, and may help in the risk stratification of patients with DCM not fulfilling current implantable cardioverter-defibrillator indications. In addition Kosiuk et al., [17] had a study on 20 patients with non ischemic cardiomyopathy. They demonstrated that left ventricle mechanical dyssynchrony which is defined as standard deviation of time to peak among the 16 segment of left ventricle by global longitudinal strain was higher in patients with ventricular arrhythmia detected by Holter than in patients that did not have ventricular arrhythmia. 


\section{Study limitations:}

- Small number of patients in our study. We could not reach statistical significance in spite of the trends to increase incidence of ventricular arrhythmia in Group I with left ventricular dyssynchrony.

- Radial strain were not evaluated at all in assessment of LV dyssynchrony.

- Using holter which can detect arrhythmia only for short duration.

\section{Recommendations:}

- More efforts must be done in another study with much larger number of patients before documenting the usefulness of assessment of left ventricular dyssynchrony by left ventricular longitudinal strain as a parameter for predicting ventricular arrhythmia in chronic ischemic patients.

- Using tools that can detect arrhythmia for longer duration such as Loop recorder as Holter detect arrhythmias for short duration.

- The prevalence of ventricular arrhythmia in patients with left ventricular dyssynchrony pre and post CRT in relation to left ventricular longitudinal and radial strain needs to be evaluated.

\section{Conclusion:}

Left ventricular dyssynchrony assessed by left ventricular longitudinal strain could be a predictor for increased risk of ventricular arrhythmia.

\section{References}

1- MOSS A.J., ZAREBA W., HALL W.J., et al.: Prophylactic implantation of a defibrillator in patients with myocardial infarction and reduced ejection fraction. N. Engl. J. Med. Mar., 21 (346): 877-83, 2002.

2- EMOND M., MOCK M.B., DAVIS K.B., et al.: Longterm survival of medically treated patients in the Coronary Artery Surgery Study (CASS) Registry. Circulation, 90: 2645-57, 1994.

3- QUINONES M.A., GREENBERG B.H., KOPELENHA, et al.: Echocardiographic predictors of clinical outcome in patients with left ventricular dysfunction enrolled in the SOLVD registry and trials: Significance of left ventricular hypertrophy. Studies of left ventricular dysfunction. J. Am. Coll. Cardiol., 35: 1237-44, 2000.

4- BUXTON A.E., LEE K.L., HAFLEY G.E., et al.: Limitations of ejection fraction for prediction of sudden death risk inpatients with coronary artery disease: Lessons from the MUSTT study. J. Am. Coll. Cardiol., 50: 1150-7, 2007.

5- MOSS A.J., HALL W.J., CANNOM D.S., et al.: Improved survival with an implanted defibrillator in patients with coronary disease at high risk for ventricular arrhythmia.
Multicenter Automatic Defibrillator Implantation Trial Investigators. N. Engl. J. Med. Dec., 26 (335): 1933-40, 1996.

6- VERMA A., MARROUCHE N.F., SCHWEIKERT R.A., et al.: Relationship between successful ablation sites and the scar border zone defined by substrate mapping for ventricular tachycardia post myocardial infarction. J. Cardiovasc. Electrophysiol., 16: 465-71, 2005.

7- ZAREBA W., MOSS A.J. and LE-CESSIE S.: Dispersion of ventricular repolarization and arrhythmic cardiac death incoronary artery disease. Am. J. Cardiol., 74: 550-3, 1994.

8- VASSALLO J.A., CASSIDY D.M., KINDWALL K.E., MARCHLINSKI F.E. and JOSEPHSON M.E.: Nonuniform recovery of excitability in the left ventricle. Circulation, 78: 1365-72, 1988.

9- HAUGAA K.H., EDVARDSEN T., LEREN T.P., GRAN J.M., SMISETH O.A. and AMLIE J.P.: Left ventricular mechanical dispersion by tissue Doppler imaging: A novel approach for identifying high-risk individuals with long QT syndrome. Eur. Heart. J., 30: 330-7, 2009.

10- HIDEKAZU TANAKA, HANS-JOACHIM NESSER, THOMAS BUCK, et al.: Dyssychrony by speckle tracking echocardiography and response to cardiacre resychronization therapy: Results of the speckle and Resynchronization (STAR) study. Eur. Heart. J., 31 (14): 1690-700, 2010.

11- KRISTINA H. HAUGAA, MARIT KRISTINE SMEDSRUD, TORKEL STEEN, et al.: Mechanical Dispersion Assessed by Myocardial Strain in Patients After Myocardial Infarction for Risk Prediction of Ventricular Arrhythmia JACC: Cardio vascular imaging Vol. 3, No. 3, by the American College of Cardiology Foundation, 2010.

12- DARRYL P. LEONG, GEORGETTE E. HOOGSLAG, EBASTIAAN R.D. PIERS, et al.: The Relationship between Time from Myocardial Infarction, Left Ventricular Dyssynchrony, and the Risk for Ventricular Arrhythmia: Speckle-Tracking Echocardiographic analysis, Journal of the American Society of Echocardiography Volume 28, Issue 4, April, Pages, 470-7, 2015,

13- BADER H., GARRIGUE S., LAFITTE S, et al.: Intraleft ventricular electromechanical asynchrony. A new independent predictor of severe cardiac events in heart failure patients. J. Am. Coll. Cardiol., 43: 248-56, 2004.

14- BHUPENDAR TAYAL, JOHN GORCSAN III, ANTONIA DELGADO MONTERO, et al.: Mechanical Dyssynchrony by Tissue Doppler Cross-Correlation is associated with Risk for Complex Ventricular Arrhythmias after Cardiac Resynchronization Therapy. Journal of the American Society of Echocardiography, December Volume 28, Issue 12, Pages 1474-81, 2015.

15- CHO G.Y., KIM H.K., KIM Y.J., et al.: Electrical and mechanical dyssynchrony for prediction of cardiac events in patients with systolic heart failure. Heart, 96: 1029$32,2010$.

16- KRISTINA H. HAUGAA, BJÖRN GOEBEL, THOMAS DAHLSLETT, et al.: Risk Assessment of Ventricular Arrhythmias in Patients with Nonischemic Dilated 
Cardiomyopathy by Strain Echocardiography. Journal of the American Society of Echocardiography, June, Volume 25, Issue 6, Pages, 667-73, 2012.

17- JEDRZEJ KOSIUK, BORISLAV DINOV and ANDREAS
BOLLMANN: Association between ventricular arrhythmias and myocardial mechanical dispersion assessed by strain analysis in patients with non ischemic cardiomyopathy. Clinical Research in Cardiology, December, Volume 104, Issue 12, pages 1072-7, 2015.

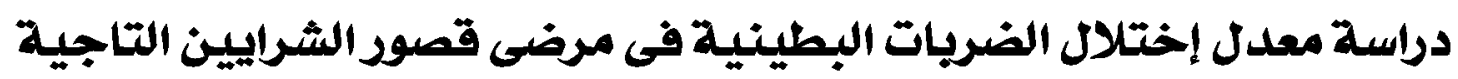

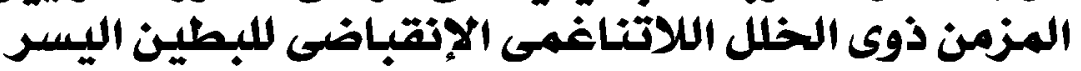

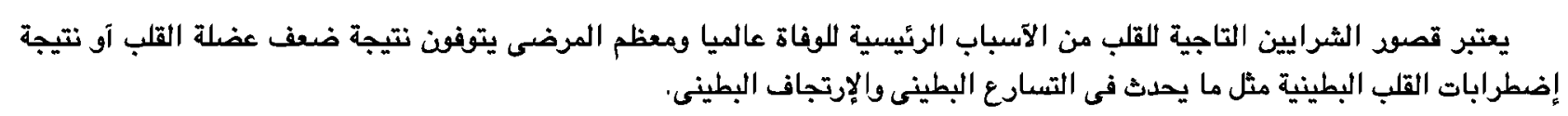
من المحتمل آن اللاتناغم الإنقباضى فى البطين الآيسر قد يكون له دود فى زيادة معدل حلوث هذه الإختلالات البطينية.

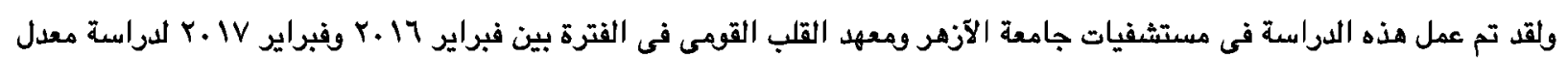

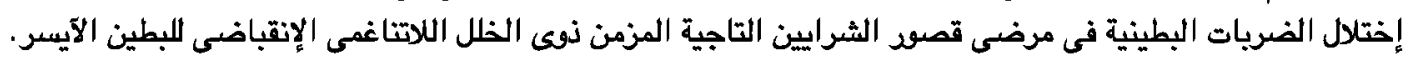

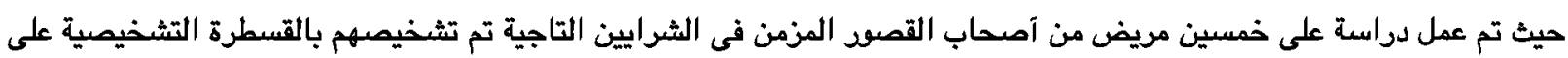

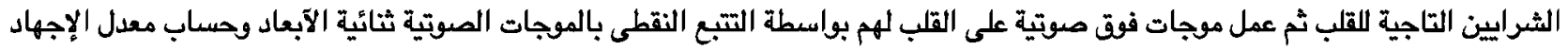

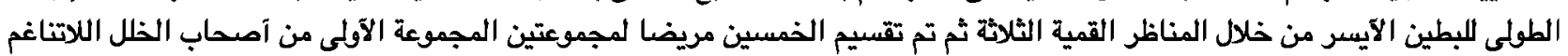

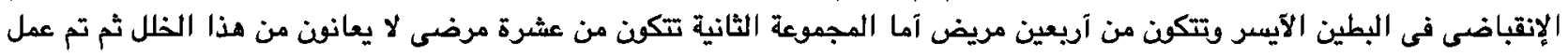

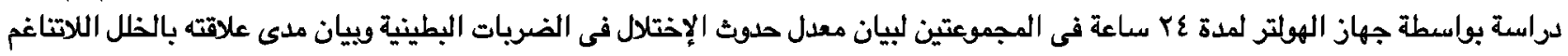
الإنقباضى فى البطين الآيسر.

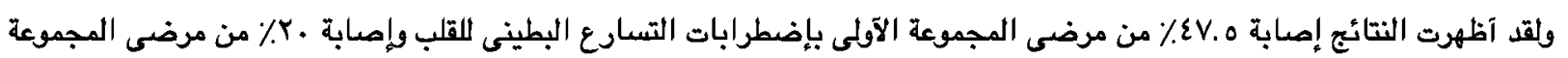

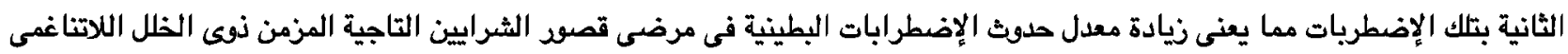
الإنقباضى البطين الآيسر. 